\title{
Qualidade de frutos de cultivares de nespereira em função do ensacamento em diferentes estádios de desenvolvimento
}

\author{
Fruits quality of loquat cultivars in a function of bagging at different development stages
}

\begin{abstract}
Alexandre Manzoni Grassi ${ }^{\mathrm{I}}$ João Alexio Scarpare Filho ${ }^{\mathrm{II}}$ Edvan Alves Chagas $^{\mathrm{III}}$ Rafael Pio $^{\mathrm{IV}}$ Moacir Pasqual $^{\mathrm{IV}}$ Leandro Henrique Guglielmin Tizato ${ }^{\mathrm{II}}$ Pollyana Cardoso Chagas ${ }^{\mathrm{IV}}$
\end{abstract}

\section{- NOTA -}

\section{RESUMO}

O ensacamento é uma operação de extrema importância no cultivo da nespereira por proporcionar qualidade à colheita de frutas, além de permitir uma minimização na utilização de produtos químicos. Entretanto, ainda existe carência de informações quanto ao momento adequado de realizar a operação, principalmente considerando-se o estádio limite de ensacamento em que se podem obter frutos de qualidade comercial. Em função do exposto, objetivou-se avaliar a qualidade dos frutos ensacados de cultivares de nespereiras em diferentes estádios. Avaliaramse as cultivares 'Mizuho', 'Mizumo', 'Mizauto', 'Centenária', 'Néctar de Cristal' e a seleção IAC NE-3 a três estádios de ensacamento, ou seja, quando os diâmetros médios deles atingiram $0,5 \mathrm{~cm}, 1,0 \mathrm{~cm}$ e $1,5 \mathrm{~cm}$. Após os frutos atingirem $o$ tamanho de acordo com cada tratamento, realizou-se o ensacamento das panículas, utilizando papel jornal. Quando maduros, os frutos foram colhidos e avaliados quanto ao comprimento, diâmetro e massa do fruto, presença de danos internos e externos. O ensacamento em diferentes estádios de desenvolvimento interferiu na qualidade dos frutos de nespereira. Frutos ensacados com diametros entre 0,5 e $1,0 \mathrm{~cm}$ foram os que apresentaram a melhor qualidade comercial. A seleção IAC NE-3 se destacou entre as nespereiras quanto às dimensões dos frutos.

Palavras-chave: Eriobotrya japonica Lindl., nêspera, raleio, manejo.

\section{ABSTRACT}

The bagging is an operation of extreme importance in the loquat culture because it provides fruit quality, and allows minimization of chemical products use. However, there is still lack of information, related to the adequate moment to carry through the operation, especially considering the limit of bagging stage, in which there are fruits of marketable quality. Therefore, this study aimed to evaluate the quality of bagged fruits of loquat cultivars in different stadiums of development. The cultivars 'Mizuho', 'Mizumo', 'Mizauto', 'Centennial', 'Crystal Nectar' and selection IAC NE-3 were evaluated in three stages of bagging, that is, when fruits reached an average diameter of $0.5 \mathrm{~cm}, 1.0 \mathrm{~cm}$ and $1.5 \mathrm{~cm}$. After fruits reached the size in accordance to each treatment, the panicles were bagged using newsprint. When mature, the fruits were harvested and evaluated regardless to length, diameter and fruit mass, presence of internal and external damages. The bagging at different developmental stages interfered in the quality of loquat fruit. bagged with diameters between 0.5 and $1.0 \mathrm{~cm}$ were the ones that had presented the best commercial quality. The IAC $N E-3$ selection detached $e$ among the loquat fruit due to its dimensions.

Key words: Eriobotrya japonica Lindl., loquat fruit, thinning, handling.

A nespereira (Eriobotrya japonica Lindl.) apresenta inflorescência que produz quantidade de frutos superior ao desejável, os quais, quando mantidos na panícula, não atingem padrões adequados à comercialização. Para aumentar o tamanho do fruto das nêsperas, podem-se ralear manualmente as flores ou o fruto, permitindo o desenvolvimento de 4 a 10 frutos por panícula. Aliado ao raleio, o ensacamento

ICoordenadoria de Assistência Técnica Integral (CATI), 13073-001, Campinas, SP, Brasil.

IEscola Superior de Agricultura Luiz de Queiróz (ESALQ), Universidade de São Paulo (USP), Piracicaba, SP, Brasil.

"IEmpresa Brasileira de Pesquisa Agropecuária (EMBRAPA), Boa Vista, RR, Brasil.

${ }^{\mathrm{IV}}$ Departamento de Agricultura (DAG), Universidade Federal de Lavras (UFLA), CP 3037, 37200-000, Lavras, MG, Brasil. E-mail: rafaelpio@dag.ufla.br.*Autor para correspondência. 
tem se mostrado uma operação eficiente na obtenção de frutos de nespereira de qualidade (PIO et al., 2008). O ensacamento não é efetivo somente no controle de pragas e doenças, mas também interfere na aparência dos frutos.

Em nespereira, a panícula é revestida com sacos de papel ou jornal, para impedir o ataque de aves e insetos, além de proteger as frutas contra a incidência de "manchas-arroxeadas", o que deprecia amplamente os frutos para o comércio, especialmente no cultivar 'Mizuho', o mais suscetível a esse distúrbio genéticofisiológico (PIO et al., 2008).

Apesar de ser uma técnica convencionalmente realizada pelos produtores, ainda há muitas dúvidas quanto ao momento adequado de ensacamento da nespereira, principalmente, considerando-se o estádio limite de ensacamento em que se podem obter frutos de qualidade comercial. Em função do exposto, objetivou-se, no presente trabalho, determinar um estádio adequado para o ensacamento propício de frutos de nespereira para a produção de frutos com qualidade superior.

$\mathrm{O}$ experimento foi realizado em área experimental do Centro Avançado de Pesquisa Tecnologia do Agronegócio das Frutas, do Instituto

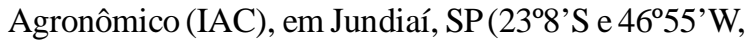
com altitude de $700 \mathrm{~m})$.

As plantas com nove anos de idade encontravam-se dispostas em espaçamento $7 \times 4 \mathrm{~m}$ e conduzidas na forma de "taça aberta". O experimento iniciou-se no mês de maio de 2008, quando se realizou a primeira poda de produção (desbaste das panículas), com as cultivares 'Mizuho', 'Mizumo', 'Mizauto', 'Centenária', 'Néctar de Cristal' e da seleção IAC NE-3. Após a primeira floração (maio), selecionaram-se panículas contento frutos de tamanhos equivalentes aos diâmetros médios de $0,5 \mathrm{~cm}, 1,0 \mathrm{~cm}$ e $1,5 \mathrm{~cm}$, os quais foram desbastados e preservaram-se apenas seis frutos por panícula. Em seguida, realizou-se o ensacamento dos frutos utilizando-se papel jornal, segundo as recomendações de PIO et al. (2008), sendo que todas as panículas foram ensacadas no mesmo dia.

$\mathrm{O}$ experimento foi instalado em delineamento em blocos ao acaso (DBC), em esquema fatorial 6 (cultivares e seleção de nespereira) x 3 (estádios de ensacamento), com quatro repetições, sendo cada repetição composta por quatro panículas. Quando os frutos atingiram o ponto de colheita, as panículas foram removidas da planta com auxílio de tesoura de poda e transportadas para o Laboratório de pós-colheita do Centro de Frutas do IAC. Os frutos foram cuidadosamente removidos da panícula, para a mensuração das seguintes variáveis biométricas: comprimento e diâmetro do fruto (realizados com auxílio de um paquímetro digital, calculando-se o valor médio das medições); massa média do fruto (realizado com auxílio de balança eletrônica, calculando-se o valor médio); presença de danos internos e externos (avaliado em função do dano causado pela mosca-dasfrutas e 'mancha arroxeada', quantificados pelas seguintes notações: 1 - sem dano, 2 - com danos leves, 3 - com danos razoáveis e 4 - frutos com danos severos). Os dados obtidos foram submetidos à análise de variância (teste $F$ ) e as médias foram comparadas pelo teste de Tukey em nível de $1 \%$ de probabilidade. Utilizou-se o Programa Computacional de Análise de Variância-SISVAR.

Pela análise estatística, constatou-se que não houve interação entre os fatores estudados, apenas diferença estatística para o comprimento, diâmetro e massa média dos frutos, em relação às diferentes cultivares de nespereira e com relação aos diferentes estádios em que os frutos foram ensacados, para as variáveis comprimento de fruto, dano internoe externo.

Verificou-se, pela avaliação da caracterização física dos frutos, que a seleção IAC NE3 foi a que apresentou os melhores resultados, exceto quando comparado com a 'Mizumo', a qual apresentou semelhante diâmetro de fruto. A seleção atingiu 46,61mm de comprimento, $38,08 \mathrm{~mm}$ de diâmetro e massa média de 33,99g (Tabela 1). Esse desempenho é importante, pois evidenciou uma superioridade das características físicas dos frutos da seleção IAC NE-3 em relação às demais cultivares.

A cultivar 'Néctar de Cristal' foi a que apresentou o menor comprimento dos frutos (31,63mm),

Tabela 1 - Comparação do comprimento (CF, mm), diâmetro (DF, $\mathrm{mm})$ e massa do fruto $(\mathrm{MF}, \mathrm{g})$, em relação às cultivares 'Mizauto', 'Néctar de Cristal', 'Mizuho', 'Mizumo', 'Centenária' e a seleção IAC NE-3. Centro APTA Frutas/IAC, Jundiaí, SP, 2009.

\begin{tabular}{llll}
\hline Cultivar & CF $(\mathrm{mm})$ & $\mathrm{DF}(\mathrm{mm})$ & $\mathrm{MF}(\mathrm{g})$ \\
\hline $\begin{array}{l}\text { 'Mizauto' } \\
\text { 'Néctar de }\end{array}$ & $36,44 \mathrm{c}$ & $30,80 \mathrm{c}$ & $16,45 \mathrm{c}$ \\
Cristal' & & & \\
'Mizuho' & $31,63 \mathrm{~d}$ & $31,02 \mathrm{c}$ & $16,70 \mathrm{c}$ \\
'Mizumo' & $38,90 \mathrm{bc}$ & $31,66 \mathrm{c}$ & $22,11 \mathrm{bc}$ \\
'Centenária' & $41,41 \mathrm{~b}$ & $35,83 \mathrm{ab}$ & $27,42 \mathrm{~b}$ \\
IAC NE-3 & $38,16 \mathrm{bc}$ & $32,60 \mathrm{bc}$ & $20,74 \mathrm{c}$ \\
CV (\%) & $46,61 \mathrm{a}$ & $38,08 \mathrm{a}$ & $33,99 \mathrm{a}$ \\
\hline
\end{tabular}

* Médias não seguidas pela mesma letra na coluna diferem entre si pelo teste Tukey, a $1 \%$ de probabilidade de erro. 
além de apresentar o menor diâmetro e massa de fruto, seguida das cultivares 'Mizauto', 'Mizuho' e 'Centenária'. Esses resultados concordam com PIO et al. (2007), que verificaram que a nespereira 'Néctar de Cristal' caracteriza-se por apresentar tamanho reduzido de frutos. Vale ressaltar que essa é uma característica intrínseca da cultivar, uma vez que ela produz frutos de formato arredondado, diferentemente dos demais, que produzem frutos de formato piriforme.

Com relação aos estádios de ensacamento, verificaram-se frutos com maiores comprimentos quando as panículas foram ensacadas com frutos nos estádios 1 e 2, ou seja, frutos com 0,5 e 1,0cm de diâmetro (Tabela 2). Por outro lado, os menores comprimentos de frutos foram obtidos quando ensacados em estádio de desenvolvimento mais avançado.

As nespereiras respondem bem à prática de raleioe, esse manejo, é realizado comumente nas plantas com a finalidade de se obter frutos maiores. Em nespereiras, por apresentarem a característica de formação de flores em panículas, ocorrem, em geral, fixação de 10 a 15 frutilhos por panícula.

Quando se analisou a incidência de danos internos, verificou-se que, quando as panículas foram ensacadas nos estádios 1 (frutos com $0,5 \mathrm{~cm}$ de diâmetro) e 2 (frutos com 1,0cm de diâmetro), houve uma redução significativa na incidência de danos internos e externos, causados principalmente pela incidência de pragas (mosca-das-frutas) e "mancha arroxeada". Em contrapartida, quando as panículas foram ensacadas no estádio 3 (frutos com $1,5 \mathrm{~cm}$ de diâmetro), observou-se que os frutos apresentaram maiores danos (Tabela 2).

OJIMA et al. (1976a) constataram que a incidência da mosca-das-frutas nas nêsperas é sempre elevada e que o ataque tem início cerca de 30 dias após o final do florescimento. Em outro trabalho, OJIMA et al. (1976b) relatam que os frutos da nespereira começam a ser atingidos pela "mancha-arroxeada" já aos 30 dias após a florada, apesar de não mostrarem os sintomas. Para ambos os casos, os referidos autores recomendam o ensacamento dos frutos no início da sua formação como o melhor método para o controle desses problemas.

O ensacamento em diferentes estádios de desenvolvimento interferiu na qualidade dos frutos de
Tabela 2 - Comparação do comprimento do fruto $(\mathrm{CF}, \mathrm{mm})$ e dano interno no fruto (DI), dano externo no fruto (DE) em relação aos estádios de ensacamento: 1 frutos com $0,5 \mathrm{~cm}$ de diâmetro, 2 - frutos com $1,0 \mathrm{~cm}$ de diâmetro, 3 - frutos com $1,5 \mathrm{~cm}$ de diâmetro. Centro APTA Frutas/IAC, Jundiaí, SP, 2009.

\begin{tabular}{lccc}
\hline Estádio de ensacamento & $\mathrm{CF}$ & $\mathrm{DI}$ & $\mathrm{DE}$ \\
& $(\mathrm{mm})$ & & \\
\hline 1 (diâmetro de $0,5 \mathrm{~cm})$ & $39,81 \mathrm{a}$ & $1,74 \mathrm{~b}$ & $1,75 \mathrm{~b}$ \\
2 (diâmetro de $1,0 \mathrm{~cm})$ & $40,68 \mathrm{a}$ & $1,78 \mathrm{~b}$ & $1,82 \mathrm{~b}$ \\
3 (diâmetro de 1,5cm) & $36,07 \mathrm{~b}$ & $2,36 \mathrm{a}$ & $2,56 \mathrm{a}$ \\
$\mathrm{CV}(\%)$ & 12,47 & 27,57 & 29,05 \\
\hline
\end{tabular}

* Médias não seguidas pela mesma letra na coluna diferem entre si pelo teste Tukey, a $1 \%$ de probabilidade de erro.

nespereira. Frutos ensacados com diâmetros entre 0,5 e $1,0 \mathrm{~cm}$ foram os que apresentaram a melhor qualidade comercial. A seleção IAC NE-3 se destacou entre as nespereiras quanto às dimensões dos frutos.

\section{REFERÊNCIAS}

OJIMA, M. et al. Intensidade de desbaste dos frutos da nespereira (Eriobotrya japonica). Bragantia, v.35, n.1, p.31-34, 1976a. Disponível em: <http://www.scielo.br/ scielo.php?script $=$ sci_arttext $\&$ pid $=$ S $0006-$ $87051976000100027 \& 1 \mathrm{ng}=\mathrm{pt} \& \mathrm{nrm}=\mathrm{i}$ so\&t $\mathrm{lng}=\mathrm{pt}>$. Acesso em: 26 nov. 2010. doi: 10.1590/S000687051976000100027 .

OJIMA, M. et al. Influência dos tipos de proteção na incidência da "mancha-arroxeada" e no desenvolvimento dos frutos da nespereira. Bragantia, v.35, n.1, p.41-44, 1976b. Disponível em: <http:// www. scielo.br/scielo.php? script $=$ sci_arttext\&pid=S0006$87051976000100029 \& \operatorname{lng}=\mathrm{pt} \& \mathrm{nrm}=\mathrm{iso} \&$ tlng $=\mathrm{pt}>$. Acesso em: 26 nov. 2010. doi: 10.1590/S0006-87051976000100029.

PIO, R. et al. Aspectos técnicos do cultivo de nêsperas. Piracicaba: ESALQ, Divisão de Biblioteca e Documentação, 2008. 30p. (Série Produtor Rural, 39).

PIO, R. et al. Produção de cultivares de nespereira na região Leste paulista. Pesquisa Agropecuária Brasileira, v.42, n.7, p.1053-1056, 2007. Disponível em: <http://www.scielo.br/ scielo.php ? script $=$ sci_arttext \& pid $=$ S $0100-$ 204X2007000700020\&lng=pt\&nrm=iso>. Acesso em: 08 jan. 2010. doi: 10.1590/S0100-204X2007000700020. 